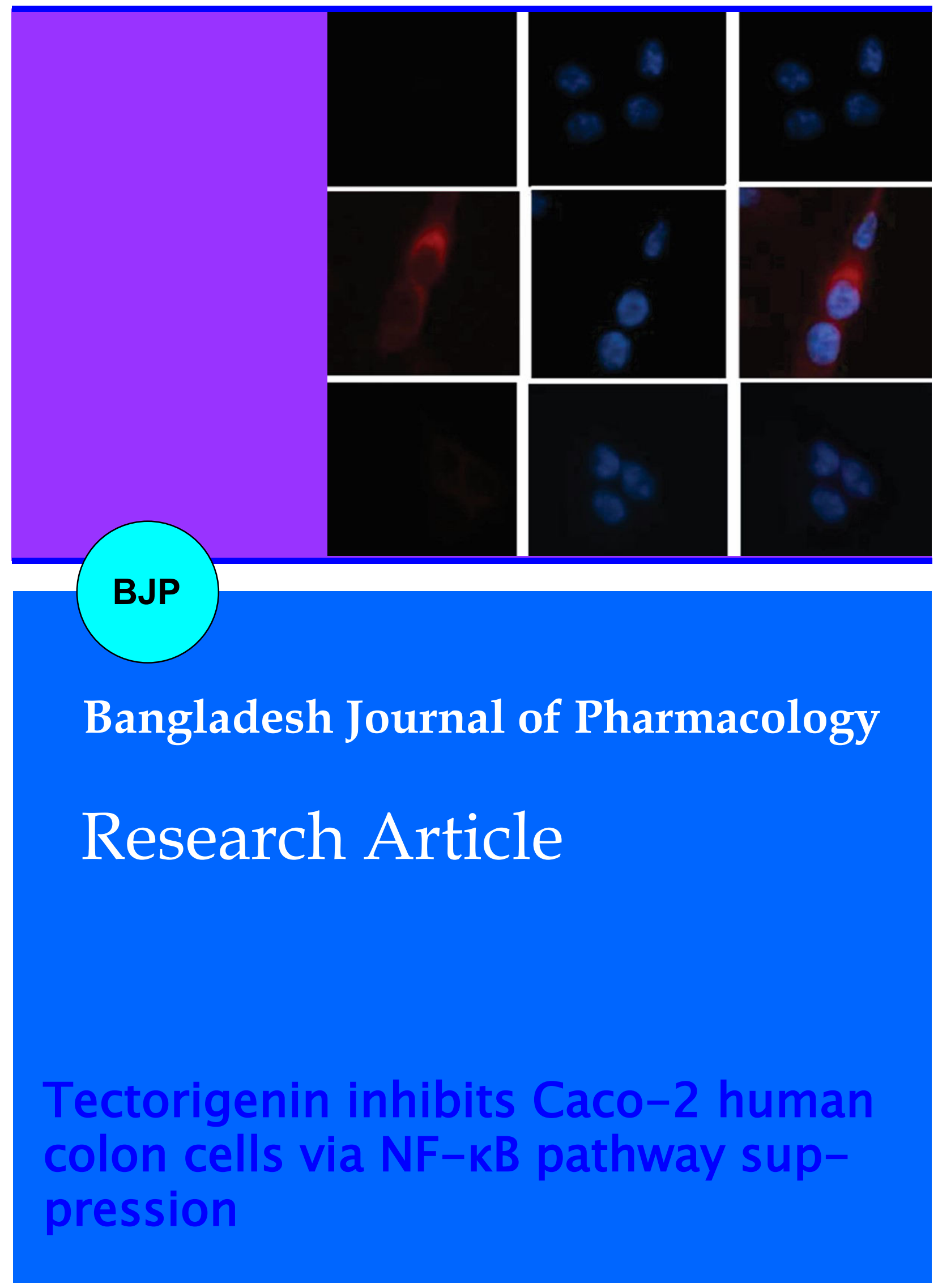




\title{
Tectorigenin inhibits Caco-2 human colon cells via NF-KB pathway suppression
}

\author{
Xiao-Yu Dai', Yong-Ming Yư ${ }^{1}$, Zheng-Fang Kong', Yi-Sheng Cao' ${ }^{1}$, Dan-Dan Huang ${ }^{2}$, Xiao- \\ Rong $\mathrm{Hu}^{2}$, Zuo-An Huang ${ }^{2}$, Yang-Yang $\mathrm{Xie}^{1}$ and Shun Zhang ${ }^{2}$
}

${ }^{1}$ Department of Anus and Intestine Surgery; ${ }^{2}$ Department of Stem Cell Laboratory, Ningbo No. 2 Hospital, Ningbo, Zhejiang 315 010, China.

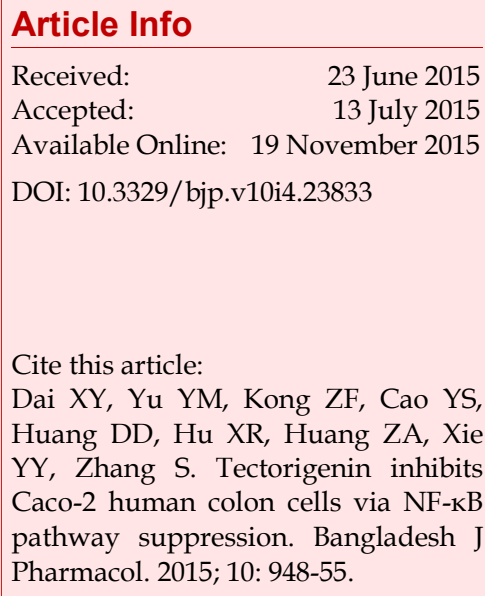

\begin{abstract}
Effective immunomodulator and pro-inflammatory cytokine, Tumor necrosis factor- $\alpha(\mathrm{TNF}-\mathrm{a})$ are considered to be responsible for connecting autoimmune pathological process and contagious diseases. TNF-a stimulates the C-X-C motif chemokine 10 (CXCL10) expression that is participated in migration of tumor, metastasis, and invasion. Tectorigenin, an o-methylated isoflavone, is present as a major portion in the Iris tectorum rhizomes. In this study, we investigated the tectorigenin effects as an anticancer drug. The obtained results showed that tectorigenin hinders the invasion of human colon cancer cells (Caco-2). We used reverse transcription PCR, q-PCR and enzyme linked immunosorbent assays to test whether the tectorigenin is involved in the inhibition of TNF-a induced CXCL-10 expression in the Caco- 2 cell lines. Further, we tested TNF- $\alpha$ induced NF-кB activity using the tectorigenin. Collective results showed that tectorigenin inhibits the CXCL10 production by using TNF- $\alpha$ via NF-kB inhibition.
\end{abstract}

\section{Introduction}

Colon cancer is one of the best inferred carcinoma from agenetic perspective, but still remains as the major cause of tumor related death, proving that most of its cancer cells are not destroyed completely by the available therapies (Fearon and Jones, 1992; Radtke and Clevers, 2005; Nelson et al., 2001; O'Connell et al., 2004). The segregation and identification of tumorigenic cancer cell lines may help to find out the novel discovery and therapeutic protocols.

In the olden traditional Chinese medicinal treatment, the Iris tectorum (a Maxim rhizome) belongs to Iridaceae family, was used as powerful anti-inflammatory agents. As one of the main ingredients of I. tectorum rhizome $(\mathrm{Wu}$ and $\mathrm{Xu}, 1992)$, tectorigenin has been reported to have in vivo, in vitro anti-angiogenic activities (Jung et al., 2003), and anti-tumor activities (Pan et al., 2008).

C-X-C motif chemokine 10 (CXCL10) is also known an interferon gamma-induced protein IP-10 or smallinducible cytokine B10 encoded by the CXCL10 gene and also acts as a chemo-attractant that regulates the inflammatory response (Neville et al., 1997). The CXCL 10 production was induced by the tumor necrosis factor - $a$ which is potent to be participated in cancer cell invasion (Shin et al., 2010). The current study deals to establish the role of phytochemicals as well as its potential target towards the human colon cancer. We proposed that tectorigenin can have great utility in lowering the effects of TNF-a induced inflammation levels which are required for the tumor growth as far as the human colon cancer is considered.
Materials and Methods
Cell culture and reagents
Caco-2 human colon cancer cells were purchased from 
Shanghai Institute of Cell biology (China). Dulbecco's modified Eagle's medium supplemented with $10 \%$ (v/v) heat inactivated fetal bovine serum (HyClone, USA) was used to grow the cells. The tectorigenin (Figure 1) used in this study was isolated from I. tectorum (Wu et al., 2010). TNF-a, glyceraldehydes-3-phosphate dehydrogenase (GAPDH) antibodies, p65/RelA, Ser-538 (phospho -RelA), IкB, and Ser-32 (phosphor-IкB) were obtained from Santa Cruz Biotechnology (USA). Anti-CXCR3 antibody, Alexa fluor 555 conjugated secondary antibodies and BAY11-7082 were purchased from Invitrogen (USA). The Invasion assay kit (with $8 \mu \mathrm{m}$ pore size)

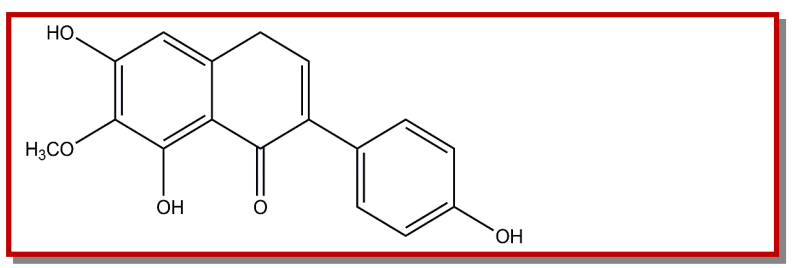

Figure 1: The structure of tectorigenin

was obtained from Cell BiolabsInc (USA).

\section{Invasion assay}

In this study, the cells were first incubated serum for about 24 hours. The density of $5 \times 10^{5}$ cells/well cell suspension in serum free medium possessing $0.1 \%$ bovine serum albumin as control vehicle, $10 \mathrm{ng} / \mathrm{mL}$ of TNF- $\alpha, 20 \mu \mathrm{M}$ of TNF- $\alpha$ and tectorigenin, $20 \mathrm{ng} / \mathrm{mL}$ of CXCL10/CXCL10 and anti-CXCR-3 antibody were then implanted on the top chamber onto a filter which is coated with polycarbonate and matrigel based membrane proteins. After 24 hours, cells present on the filter top were detached using cotton-swabs and the remaining cells that are located in the bottom filters were subjected for staining and then followed by extraction and quantification at $560 \mathrm{~nm}$ as per the instructions given in the manufacture's kit. This method was performed based on the reported literature (Shin et al., 2010).

\section{Cell proliferation assay}

The cell proliferation was determined by using Cell counting kit-8 (Dojindo Molecular Technologies, USA). In this experiment, the Caco- 2 colon cancer cells at a density of $2 \times 10^{3}$ cells/well were cultured onto 96-well plates and then treated with tectorigenin $(20 \mu \mathrm{M})$ for different time period.

\section{Clonogenic survival assay}

In brief, Caco- 2 cells at a density of $5 \times 10^{3}$ cells/well were cultured using 24-well plates in a DMEM medium containing $10 \%$ fetal bovine serum. Then the seeded cells were then treated with various tectorigenin concentrations for one week and fixed with glutaraldehyde $(6 \%)$ and then crystal violet $(0.1 \%)$ was used for staining.

Reverse transcription-polymerase chain reaction (RTPCR) and quantitative real-time PCR (qRT-PCR) analyses

Forward,5'-GAAATTATTCCTGCAAGCCAATTT-3, reverse, 5'-TCACCCTTCTTTTTCATGTAGCA-3 genespecific primers and glyceraldehyde 3-phosphate dehydrogenase (GAPDH, forward, 5' ACCCACTCCTCCACCTTTG-3'; reverse, 5'CTCTTGTGCTCTTGCTGGG-3') were used for CXCL10RT-PCR analysis. The sequences of the qRTPCR primers were as follows: forward CXCL10, 5'AGCAAGGAAAGGTCTAAAAGATCTCC-3'; reverse CXCL10, 5'-AGTCCCACTCAGACCCAGCAGG-3'; CXCL10 TaqMan probe, 5'-FAM-AGGCAGCCTCTGTGTGGTCCATCCTT-BHQ-3'; forward GAPDH, 5'TCGACAGTCAGCCGCATCTTC-3'; reverse GAPDH, 5'-CGCCCAATACGACCACCTCCG-3'; and GAPDH TaqMan probe, 5'-Yakima Yellow TM CGTCGCCAGCCCAGCCACGC-BHQ-1-3'. The PCR conditions for all primers were as follows: Hold for 5 min at $94^{\circ} \mathrm{C}$, followed by 30 cycles consisting of denaturation at $94^{\circ} \mathrm{C}(30 \mathrm{sec})$, annealing at $55^{\circ} \mathrm{C}(30 \mathrm{sec})$, and elongation at $72^{\circ} \mathrm{C}(1 \mathrm{~min})$. The amplified products were subjected to electrophoresison a 1\% agarose gel. The relative expression level of CXCL10 mRNA was measured by quantitative real-time PCR (qRT-PCR) using a Taq-Man-iQsupermix kit (Bio-Rad, USA) and a Bio -Rad iCycler iQ according to the manufacturer's instructions. The relative fold changes were normalized for GAPDH mRNA in the same samples.

\section{Enzyme linked immunosorbent assay (ELISA)}

At first the Caco-2 cells were incubated with serum for about 24 hours and then followed by $10 \mathrm{ng} / \mathrm{mL}$ TNF-a treatment in $0.5 \%$ fetal bovine serum for next 24 hours. After this, the cultured media were collected and subjected for CXCL10 protein level measurement. This was performed using human CXCL10 ELISA kit (R\&D systems, USA) as per the supplier's instructions.

\section{CXCL-10 promoter assay}

Briefly, the Caco- 2 colon cancer cells at a density of $2 \times$ $10^{3}$ cells/well were cultured onto 24 -well plates and then transfected with CXCL10 promoter construct $(0.5$ $\mu \mathrm{g}$ ) by using lipofectamine 2000 (Invitrogen) based on manufacturer's instructions. The mammalian expression vectors of about $0.2 \mu \mathrm{g}$ for RelA/the NF-kB suppressor/(S32A/S38A) for IkBa were also added. In order to determine the efficiency of its transfection, RLUC (Renilla luciferase) of about 50 ng was added in all samples as a pRL-null encoding plasmid. This was investigated using Dual-glo luciferase assay system (Promega, USA) for firefly and renilla luciferase activities as reported in earlier literature (Wynendaele et al., 2010). Centro LB 960 luminometer (Metabion 
International, Germany) was used to measure its luminescence.

\section{NF- $\kappa B-d e p e n d e n t$ transcriptional activity}

Caco-2 cells were cultured in 12-well plates and transfected with $0.1 \mu \mathrm{g}$ of the $5 \times \mathrm{NF}-\mathrm{kB}-\mathrm{Luc}$ plasmid, along with $50 \mathrm{ng}$ of the pRL-nullplasmid encoding Renilla luciferase. Firefly and Renilla luciferase activities were measured using the Dual-Glo Luciferase Assay System (Promega) and normalized to Renilla activity. The luminescence was measured with a Centro LB960 luminometer (Metabion International, Germany).

\section{Western blot}

Cell lysates possessing protein of $10 \mu \mathrm{g}$ were first separated and then transferred into filters made of nitrocellulose. Later, these blots were treated with the antibodies as per the experimental method (Shin et al., 2010). Caco-2 cells were also lysed based on this reported method.

\section{Immunofluorescent analysis}

The Caco-2 cells were seeded on to the cover slips treated as control and then treated with tectorigenin of $20 \mu \mathrm{M}$ for about $30 \mathrm{~min}$ before inducement with TNF-a (10 ng/mL). We used $4 \%$ para-formaldehyde to fix it and permeabilized with Triton X-100 (0.1\%) and bovine serum albumin $(2 \%)$. The red signal phosphorylation of RelA was determined by treatment with Ser-536
(phosphor-RelA) antibody and Alexa fluor 555 conjugated secondary antibody for about 2 hours and 30 min respectively. The blue signal, nuclear DNA was measured using Hoechst 33258 staining $(1 \mu \mathrm{g} / \mathrm{mL})$ for $10 \mathrm{~min}$. EVOSfl fluorescence microscope (Berthold Technologies, Germany) was used to determine the labeled cells.

\section{Statistical analysis}

We used Student's t-test and ANOVA test to measure the significant difference in which $p$ values $<0.05$ were considered as least significant. All the observed data were expressed as means \pm standard deviation of at least 3 independent experiments.

\section{Results}

\section{Effect of tectorigenin on invasion activity}

Matrigel based trans-well migration assays were carried out to investigate the tectorigenin effects on invasion activity of human colon cancer cell lines. Upon treatment with TNF- $a$, the count of Caco-2 invasive cells present on the bottom surface of coated membrane filters was found to be increased and upon treatment with tectorigenin or BAY 11-7082, a NF- $\mathrm{kB}$ inhibitor, this effect was totally inhibited (Figure 2A). Cell growth rate was not altered by tectorigenin within 24 hours and

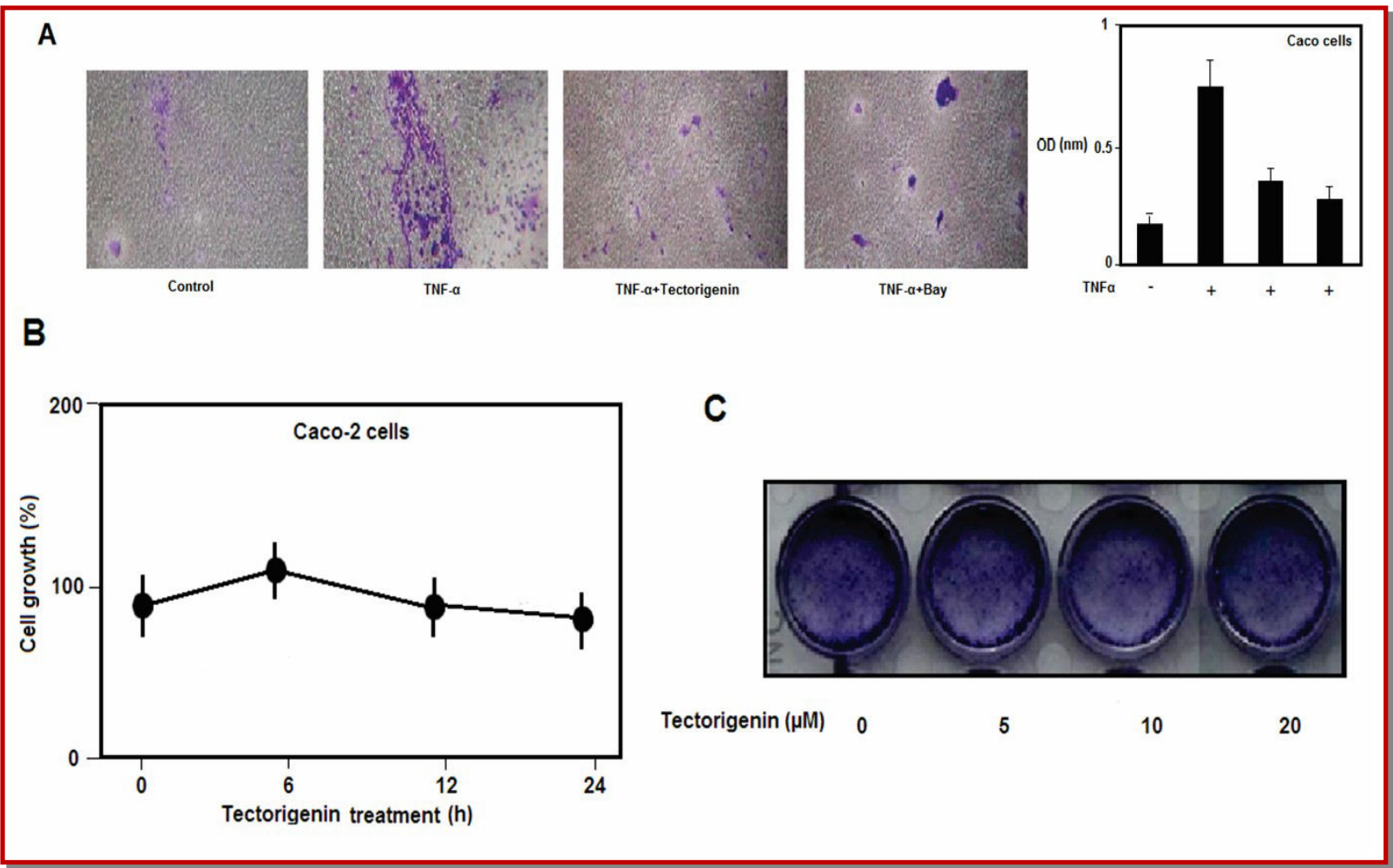

Figure 2: Tectorigenin inhibitory effect on TNF- $\alpha$ induced invasive studies (A) Treatment of Caco-2 cells with $10 \mathrm{ng} / \mathrm{mL}$ TNF- $\mathrm{a}$ in the presence or absence of tectorigenin $(20 \mu \mathrm{M}) /$ BAY11-7082 $(20 \mu \mathrm{M})$. (B) Tectorigenin $(20 \mu \mathrm{M})$ treatment with Caco-2 cells in different time periods (6-24 hours). (C) Caco-2 cells treated with different concentrations of tectorigenin (0, 5, 10 or $20 \mu \mathrm{M})$ 


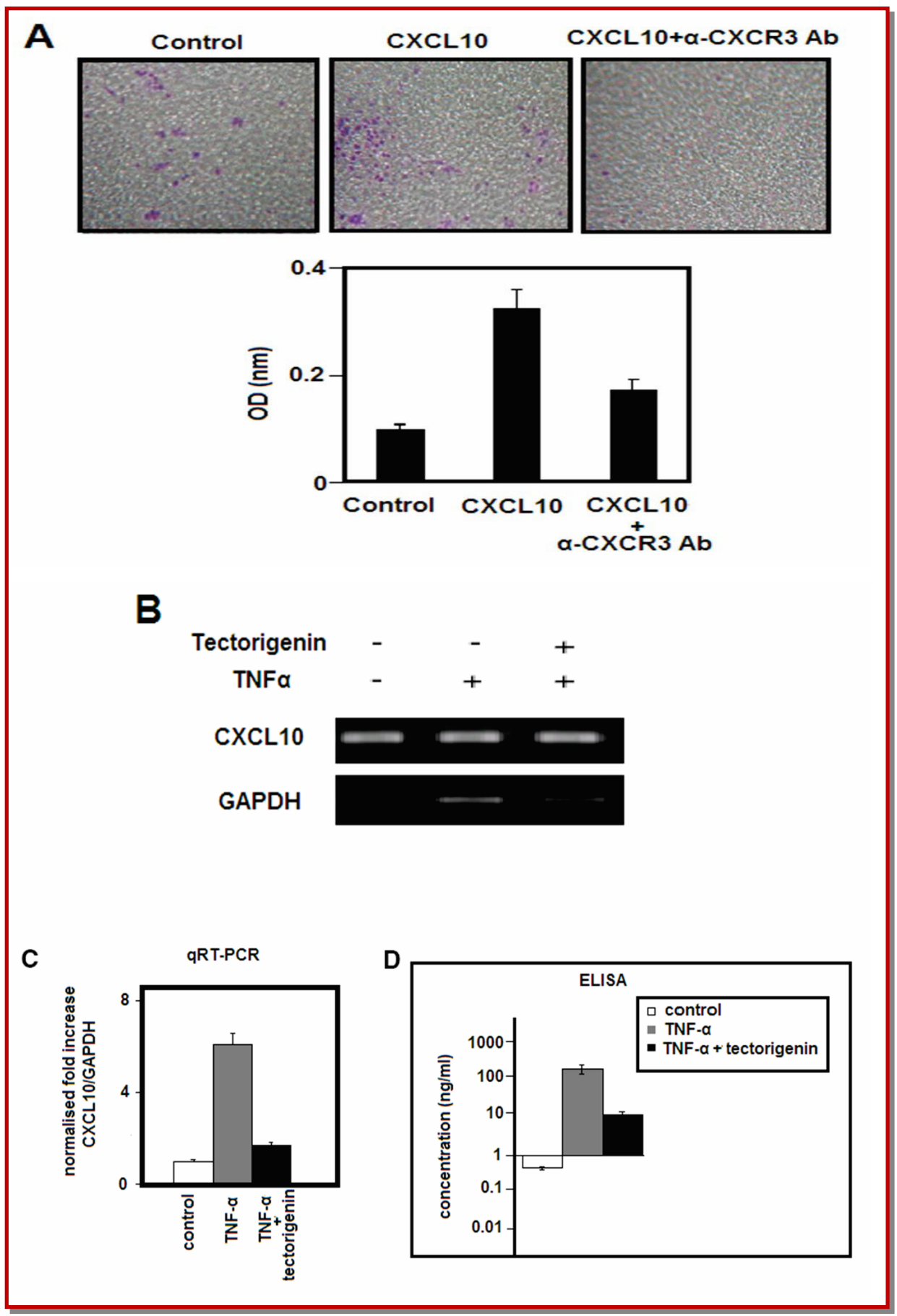

Figure 3: Tectorigenin inhibitory effect on TNF-a induced CXCL10 expression. (A) Caco-2 cells stimulation with control or CXCL10 $(20 \mathrm{ng} / \mathrm{mL})$ in the presence or absence of anti-CXCR3 antibody $(5 \mu \mathrm{g} / \mathrm{mL})$. (B) CXCL10 and GAPDH mRNA expression analysis: Caco-2 cells alone or treated with TNF- $\alpha(10 \mathrm{ng} / \mathrm{mL})$ in the absence or presence of tectorigenin $(20 \mu \mathrm{M})$ for 12 hours. (C) mRNA quantification using RT-PCR samples prepared in (A). (D) ELISA test: Caco-2 cells alone or treated with TNF- $(10 \mathrm{ng} / \mathrm{mL})$ in the absence or presence of tectorigenin $(20 \mu \mathrm{M})$ for 12 hours. All the data shown indicated the mean \pm SD for one experiment performed in triplicates

clonogenic survival activity within one week, respectively (Figure 2B and 2C). That is, tectorigenin exposure arrested the invasion effect of Caco-2 cancer cells upon TNF- $a$ inducement.
Effect of tectorigenin on TNF-a-induced CXCL10 expression

The treatment of CXCR-3 antibody helps to considerably block the CXCL10 enhanced invasively migra- 
ted Caco-2 cancer cells (Figure 3A). This suggested that CXCL10 contributed for TNF-a inducement of invasive property of Caco-2 cells. Caco-2 cells underwent tectorigenin pretreatment before TNF-a inducement in order to determine the tectorigenin effects upon TNF-a induced CXCL10 expression. RT-PCR results showed that CXCL10 mRNA expression was up-regulated strongly by TNF-a (Figure 3B). However, $30 \mathrm{~min}$ tectorigenin $(20 \mu \mathrm{M})$ pre-treatment significantly blocked TNF-a induced CXCL10 mRNA expression. Further, we accurately measured the CXCL10 transcripts fold inducements using qRT-PCR. Analysis showed that 6fold CXCL10 transcripts were increased upon treatment with TNF-a whereas only 1.5-fold increase was observed with tectorigenin addition (Figure 3C). These results are consistent with RT-PCR data. In addition, we used ELISA test for TNF-a treated Caco-2 cells conditioned medium to investigate whether tectorigenin can prevent the production of CXCL10 protein by
TNF-a (Figure 3D). Results showed that treatment with TNF- $\alpha$ produced $150 \mathrm{ng} / \mathrm{mL}$ of CXCL10 protein but this was reduced to $11 \mathrm{ng} / \mathrm{mL}$ upon tectorigenin addition. All these results suggested that tectorigenin can effectively inhibit the TNF-a induced CXCL-10 expression in the human colon Caco-2 cells.

\section{Stimulation of CXCL-10 promoter activity by TNF-a via $N F-\kappa B$}

To testify the trans-activity of CXCL10 promoter induced by NF- $\mathrm{KB}$ in Caco-2 cells, we first co-transfected the p65/RelA NF-kB expression plasmid into Caco- 2 cells along with pCXCL-10-Luc $(-750 /+8)$, the CXCL-10 promoter construct and then measured the luciferase activity. Figure $4 \mathrm{~A}$ showed that TNF-a induced CXCL10 promoter activity was elevated by the p65/RelA NF-kB exogenous expression. Further, TNF-a induced CXCL10 promoter activity was powerfully repealed by S32A/S36A expression, the IKB-a mutant
A

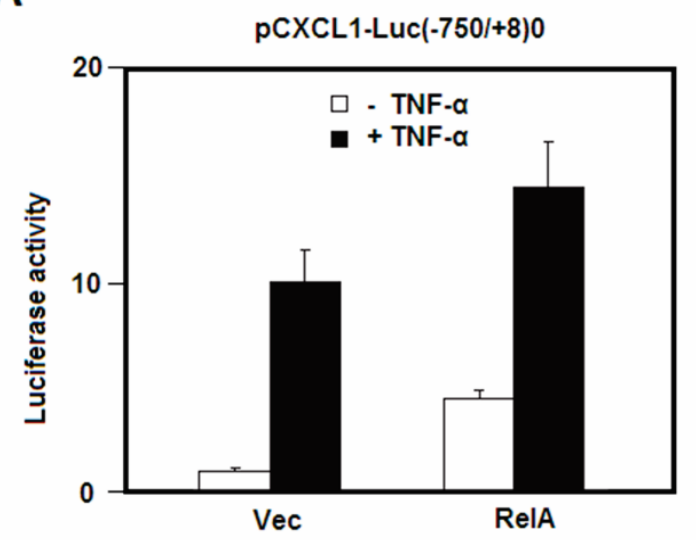

B

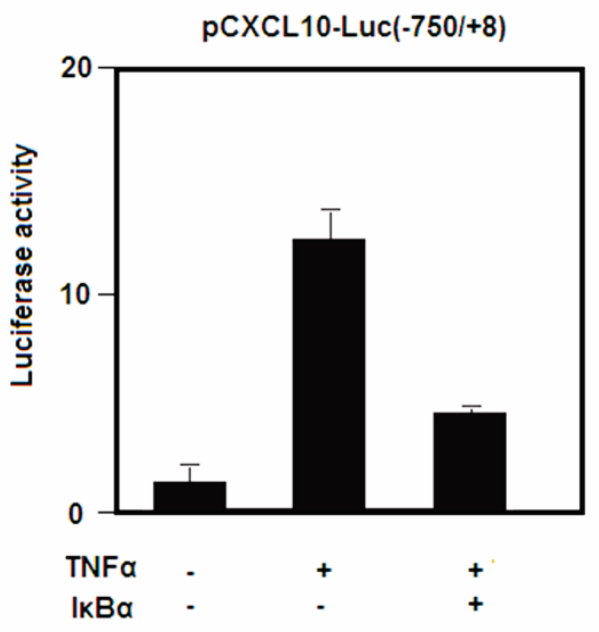

(S32A/S36A)

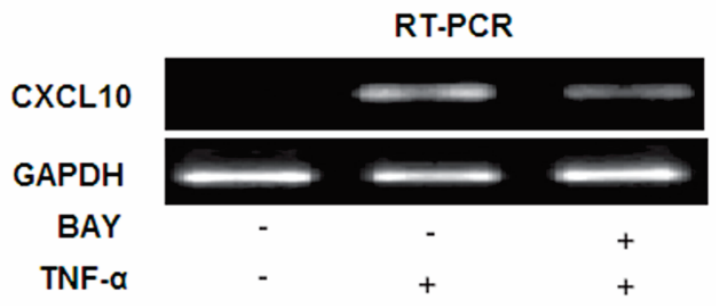

Figure 4: NF-kB effect on TNF-a induced CXCL10 promoter assay. (A) Co-transfection of Caco-2 cells with $0.2 \mu \mathrm{g}$ of pCXC-10-Luc $(-750 /+8)$ and $0.2 \mu \mathrm{g}$ of expression plasmids for p65/RelA or empty vector, along with $50 \mathrm{ng}$ of expression plasmid for Renilla luciferase (pRL-null) for normalization of transfection efficiency. (B) Co-transfection of Caco-2 cells with $0.2 \mu \mathrm{g}$ of pCXC-10-Luc($750 /+8)$ and $0.2 \mu \mathrm{g}$ of expression plasmids for IкB, along with $50 \mathrm{ng}$ of expression plasmid for Renilla luciferase (pRL-null) for normalization of transfection efficiency

At 48 hours post transfection, cells were treated alone or with TNF- $\mathrm{a}(10 \mathrm{ng} / \mathrm{mL})$ for 8 hours, and firelfly luciferase activity was measured and normalized to Renilla activity. (C) Treatment of Caco-2 cells with $10 \mathrm{ng} / \mathrm{mL}$ TNF- $\alpha$ in the presence or absence of tectorigenin (20 $\mu \mathrm{M}) / \mathrm{BAY} 11-7082$ (20 $\mu \mathrm{M})$ for 12 hours. All the data shown indicated the mean \pm SD for one experiment performed in triplicates 
construct which suppressed NF-kB activity (Figure 4B). We further investigated the crucial role of NF- $\mathrm{KB}$ by using NF-kB chemical inhibitor BAY 11-7082 and observed the considerable decrease in the TNF-a induced CXCL-10 mRNA expression (Figure 4C). All these results inferred the involvement of NF-kB in the TNF- $\alpha$ induced CXCL-10 promoter activity in human colon Caco-2 cells.

\section{Tectorigenin inhibits TNF-a induced CXCL-10 promoter activity}

To monitor the necessity of NF-kB binding site in the TNF- $\alpha$ induced CXCL10 promoter activity, we transfect the Caco-2 cells with wild type construct bearing binding sites for NF- $\mathrm{kB}$ or with mutant construct bearing disordered NF-kB sites, $(-750 /+8$ \& $-250 /+8)$ and $(-250 /+8 \mathrm{mt} N F-\mathrm{KB})$ respectively. Analysis results indicated upon TNF- $\mathrm{a}$ treatment the promoter construct $(-750 /+8$ or $-250 /+8)$ bearing the NF-kB binding sites displayed raise in the promoter activity however this TNF-a inducibility was markedly reduced by the tectorigenin treatment (Figure 5).

\section{Tectorigenin inhibition effect on TNF-a induced NF- $\kappa B$ activation}

To monitor the tectorigenin inhibition on TNF- $\alpha$ induced NF-kB activity in human colon Caco- 2 cells, we studied the tectorigenin impact on TNF-a induced IкB phosphorylation using western blot analysis. Results shown in Figure 6A identified that phosphorylation of IкB on Ser-32 was increased by TNF- $\alpha$ and this further reduced the total IKB levels. Also it indicated that there was an increase in the p-65/RelA phosphorylation level on Ser-536 by TNF-a but there was no alteration in its level (Figure 6A). In this state, tectorigenin pretreatment overruled both IKB and p-65/RelA TNF- $a$ induced phosphorylation and hence suggested that NF-kB activity was blocked by tectorigenin via IKB inhibition mainly at IKK.

The further evidence of the tectorigenin inhibition on NF-kB was gained from p-65/RelA phosphorylation status using immunofluorescent microscopic analysis. We observed the strong effect while staining phospho RelA at Ser536 in response with tectorigenin treatment both in nuclear and peri-nuclear regions (Figure 6B). Tectorigenin effectively inhibits the NF- $\mathrm{kB}$ activation upon treatment with TNF-a.

In addition, whether tectorigenin inhibition effect on NF-kB was working through link with NF-kB depended transcription activity, we carried out NF- $\mathrm{kB}$ cis-acting reporter assay via transfection of Caco-2 cells with $5 \times$ NF-kB-luc plasmid and the transcription activity controlled by NF-кB was identified from luciferase activity. Results displayed 14-fold increase in the TNF-a induced NF- $\mathrm{kB}$ transcription activity whereas upon

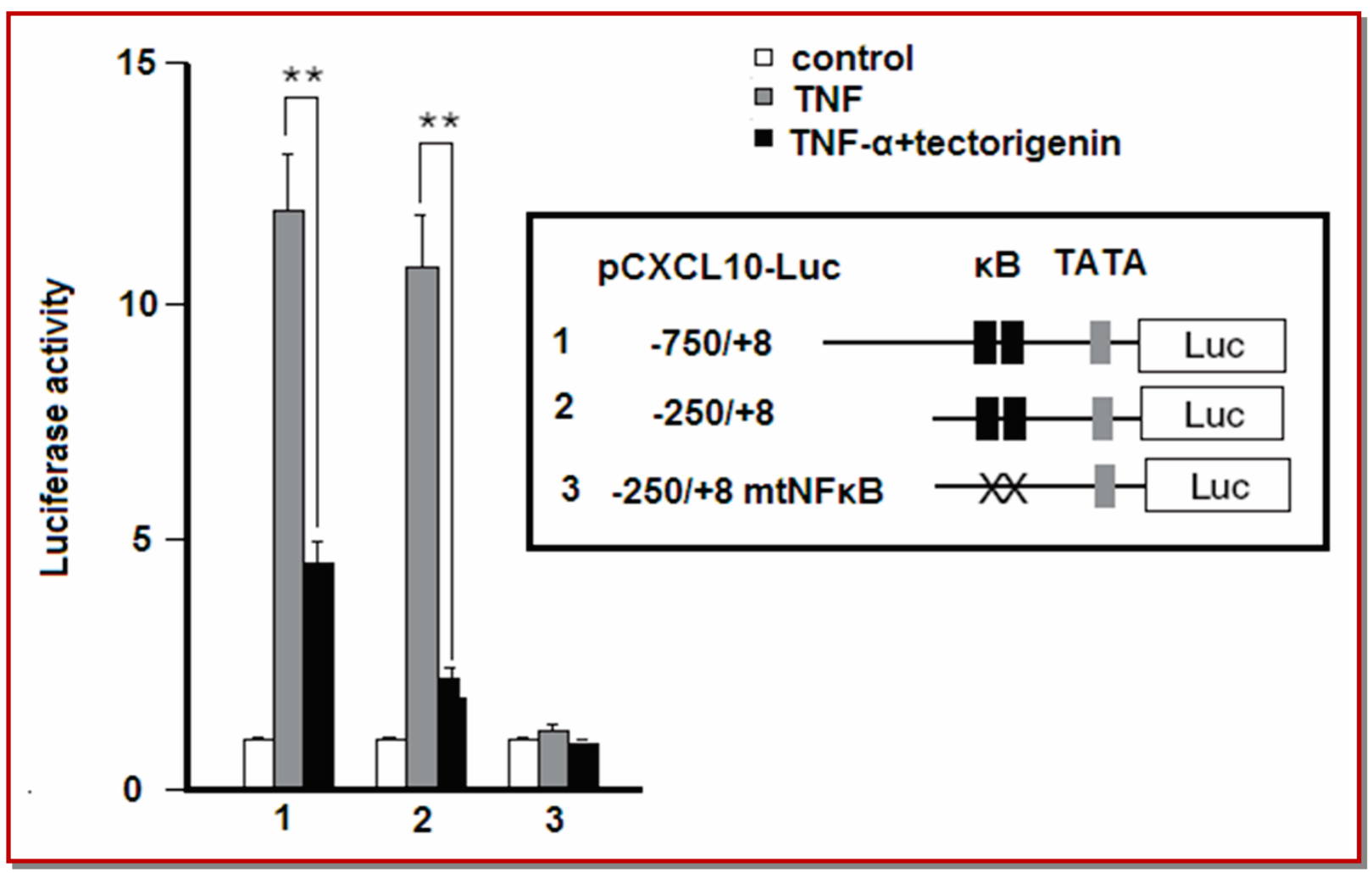

Figure 5: TNF- a induced CXCL-10 promoter activity. Treatment of Caco-2 cells with $10 \mathrm{ng} / \mathrm{mL}$ TNF- $\alpha$ or TNF- $\alpha$ plus tectorigenin $(20 \mu \mathrm{M})$ for 8 hours and firefly luciferase activity was measured and normalized to Renilla activity. All the data shown indicated the mean $\pm \mathrm{SD}$ for one experiment performed in triplicates 


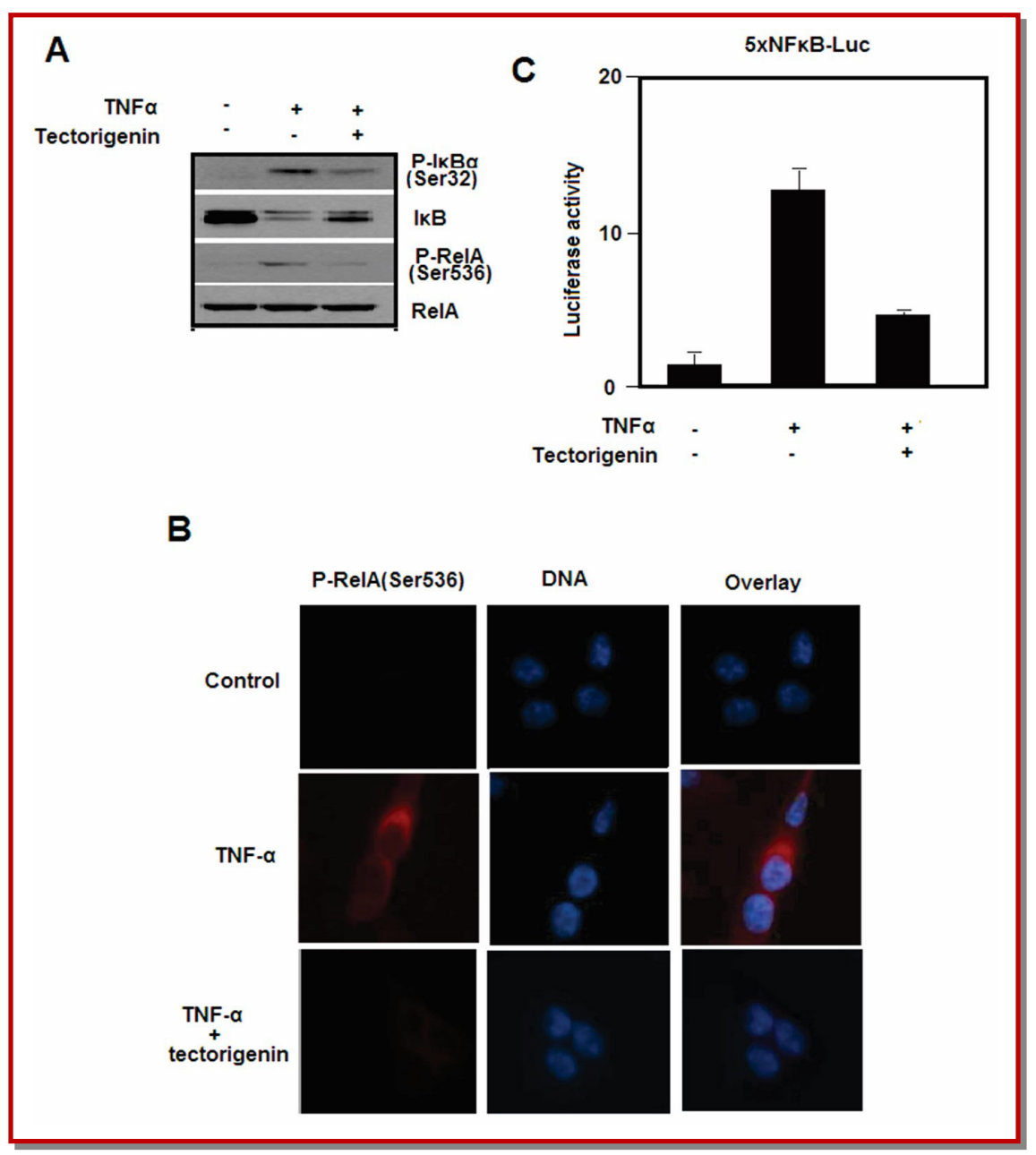

Figure 6: Tectorigenin inhibitory effect on TNF-a induced activation of NF-KB. (A) Caco-2 cells alone or treated with $10 \mathrm{ng} / \mathrm{mL}$ TNF- $\alpha$ plus tectorigenin $(20 \mu \mathrm{M})$ for 12 hours. (B) Caco-2 cells tectorigenin $(20 \mu \mathrm{M})$ for 30 min before stimulation with TNF- $\alpha(10$ $\mathrm{ng} / \mathrm{mL}$ ) for $30 \mathrm{~min}$. The overlay images are shown on the right. (C) Caco-2 cells alone or treated with $10 \mathrm{ng} / \mathrm{mL} \mathrm{TNF}-\mathrm{a}$ plus tectorigenin $(20 \mu \mathrm{M})$ for 8 hours and luciferase activity was measured. All the data shown indicated the mean \pm SD for one experiment performed in triplicates

treatment with tectorigenin. This activity was reduced to 3-fold (Figure 6C). This clearly indicated that tectorigenin suppresses NF-kB transcription activation resulting in lowering the TNF- $\mathrm{a}$ induced CXCL10 expression.

\section{Discussion}

The infiltrating inflammatory cells and stromal cells are responsible for the major production of inflammatory cytokine called TNF-a. In this work, we have reported that the O-methylated isoflavone, tectorigenin suppresses TNF- $\alpha$ motivated CXCL10 expression via reduced behavior of NF-kB based transcription activity in human Caco-2 cancer cell lines. In addition to this, tectorigenin displayed the repressive activity on the TNF- $a$ induced migration and invasive activity of Caco2 human colon cancer cells. These results disclosed that tectorigenin is capable of averting the colon carcinoma mediated through blockade of TNF-a induced inflammatory reactions.

Further, we observed that the invasive migration activity in Caco-2 cells was promoted by CXCL10 expression and this was considerably nullified by subjected to neutralizing CXCR-3, a CXCL10 receptor and this declared that CXCL10 played a vital role in TNF-a induced invasion responses in Caco- 2 cells. Hence, we measured the tectorigenin effects on CXCL10 expression following treatment with TNF-a. Observation of protein expression results from the analyses of RT-PCR, QRT-PCR and ELISA methods clearly showed that tectorigenin attenuated CXCL10 mRNA. Furthermore, we found that tectorigenin strongly inhibited TNF- $\alpha$ induced CXCL10 promoter responses indicating that tectorigenin regulates CXCL10 expression at transcription level. 
Previous results showed that CXCL10 promoter activity was stimulated by TNF- $a$ which was mediated through $\mathrm{NF}-\mathrm{kB}$ cis acting reaction component within the CXCL10 promoter at mesenchymal stem cells (Shin et al., 2010). The binding site NF-kB disruption within the CXCL10 promoter in Caco-2 cells almost totally eradicated TNF-a inducibility of CXCL10 promoter activity and also the ectopic responses of NF- $\mathrm{kB}$ nullified TNF- $\mathrm{a}$ induced CXCL10 promoter activity. Further suppression of NF-kB activity developed in the reduction of TNF- $\alpha$ induced CXCL10 mRNA expression and this showed that CXCL10 gene transcription activation chiefly resting on the NF- $\mathrm{kB}$ cis acting response ingredient.

To ascertain whether tectorigenin controls the pathway of NF-kB signaling, we trailed to methodically examine the existence of native and phosphorylated availability of IкB either in the presence or absence of tectorigenin. The obtained results indicated that IкB phosphorylation on Ser32 was induced by TNF- $\alpha$ and stimulated the IKB degradation in Caco-2 colon cancer cells.

We also found that tectorigenin hindered TNF- $\mathrm{a}$ induced NF-KB phosphorylation on Ser-536.

$\mathrm{NF}-\mathrm{kB}$ cis-acting reporter assay revealed tectorigenin influenced a reduced effect on NF- $\mathrm{kB}$ dependent transcription response. Based on these results, we suggested that tectorigenin can serve as a powerful antitumor agent in the tumor micro-environment.

\section{Conclusion}

Tectorigenin can effectively reduce CXCL10 yield inhibiting through the action of TNF-a induced NF-kB responses in the Caco- 2 colon cancer cell lines. NF-kB response being acting as a crucial requirement for inflammation-piloted tumor formation, blockade of TNF- $\alpha$ induced inflammatory actions can be the favorable strategy for cancer therapy. We proposed the beneficial effect of tectorigenin in the prevention of TNF - $\alpha$ induced inflammatory activity in the human colorectal cancer.

\section{Acknowledgement}

The authors thank the Ningbo Science and Technology Innovation Team Project (2011B82016) for providing the financial support for our research work.

\section{References}

Fearon ER, Jones PA. Progressing toward a molecular description of colorectal cancer development. FASEB J. 1992; 6: 2783 -90 .

Joyce JA, Pollard JW. Microenvironmental regulation of metastasis. Nat Rev Cancer. 2009; 9: 239-52.

Jung SH, Lee YS, Lee S, Lim SS, Kim YS, Ohuchi K, Shin KH. Anti-angiogenic and anti-tumor activities of isoflavonoids from the rhizomes of Belamcanda chinensis. Planta Med. 2003; 69: 617-22.

Nelson H, Petrelli N, Carlin A, Couture J, Fleshman J, Guillem J, Miedema B, Ota D, Sargent D, National Cancer Institute Expert Panel. Guidelines 2000 for colon and rectal cancer surgery. J Natl Cancer Inst. 2001; 93: 583-96.

Neville LF, Mathiak G, Bagasra O. The immunobiology of interferon-gamma inducible protein $10 \mathrm{kD}$ (IP-10): A novel, pleiotropic member of the $\mathrm{C}-\mathrm{X}-\mathrm{C}$ chemokine superfamily. Cytokine Growth Factor Rev. 1997; 8: 207-19.

O'Connell JB, Maggard MA, Ko CY. Colon cancer survival rates with the new American Joint Committee on Cancer sixth edition staging. J Natl Cancer Inst. 2004; 96: 1420-25.

Pan $\mathrm{CH}$, Kim ES, Jung SH, Nho CW, Lee JK. Tectorigenin inhibits IFN-gamma/LPS-induced inflammatory responses in murine macrophage RAW 264.7 cells. Arc Phar Res. 2008; 31: $1447-56$.

Radtke F, Clevers H. Self-renewal and cancer of the gut: Two sides of a coin. Science 2005; 307: 1904-09.

Shin SY, Nam JS, Lim Y, Lee YH. TNF alpha-exposed bone marrow-derived mesenchymal stem cells promote locomotion of MDA-MB-231 breast cancer cells through transcriptional activation of CXCR3 ligand chemokines. J Biol Chem. 2010; 285: 30731-40.

Wu JH, Wang YR, Huang WY, Tan RX. Anti-proliferative and pro-apoptotic effects of tectorigenin on hepatic stellate cells. World J Gastroenterol. 2010; 16: 3911-18.

Wu YX, Xu LX. Analysis of isoflavones in Belamcanda chinensis (L.) DC. and Iris tectorum Maxim by square wave voltammetry. Yaoxue Xuebao 1992; 27: 64-68.

Wynendaele J, Böhnke A, Leucci E, Nielsen SJ, Lambertz I, Hammer S, Sbrzesny N, Kubitza D, Wolf A, Gradhand E, Balschun K, Braicu I, Sehouli J, Darb-Esfahani S, Denkert C, Thomssen C, Hauptmann S, Lund A, Marine JC, Bartel F. An illegitimate microRNA target site within the 3' UTR of MDM4 affects ovarian cancer progression and chemosensitivity. Cancer Res. 2010; 70: 9641-49.

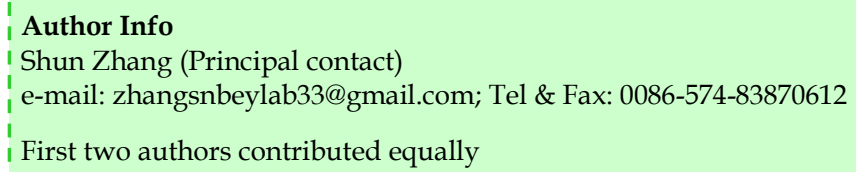

